Research Article

\title{
Deformation and Stress Distribution of the Effective Water-Resisting Rock Beam under Water-Rock Coupling Action inside the Panel Floor
}

\author{
Baojie Fu, ${ }^{1,2,3}$ Hualei Zhang $\mathbb{D}^{1,3}$ Min Tu, $^{1,3}$ and Xiangyang Zhang ${ }^{1,3}$ \\ ${ }^{1}$ School of Mining and Safety Engineering, Anhui University of Science and Technology, Road Taifeng No. 168, Huainan, \\ Anhui 232001, China \\ ${ }^{2}$ State Key Laboratory for GeoMechanics and Deep Underground Engineering, China University of Mining and Technology, \\ Xuzhou, Jiangsu 221116, China \\ ${ }^{3}$ Key Laboratory of Coal Mine Safety and Efficiently Caving of Ministry of Education, Anhui University of Science and \\ Technology, Huainan, Anhui 232001, China
}

Correspondence should be addressed to Hualei Zhang; zhanghl@aust.edu.cn

Received 7 May 2018; Accepted 21 June 2018; Published 17 October 2018

Academic Editor: Hailing Kong

Copyright (c) 2018 Baojie Fu et al. This is an open access article distributed under the Creative Commons Attribution License, which permits unrestricted use, distribution, and reproduction in any medium, provided the original work is properly cited.

The stability of panel floor, which is above confined water, is the key to determine the water inrush from the panel floor. Based on the characteristics of "lower three zones" of the panel floor, the mechanics analysis model of a floor water-resisting rock beam is established. Then, by the principle of virtual work and energy functional variational conditions, the trends of deflection and internal stress are researched in the effective water-resisting rock beam under the combined action of mining stress and water pressure. And how to determine its stability is acquired. According to the geological and mining conditions of A3 coal seam in Panxie mining area of Huainan Mining Group, three factors influencing on the stability of the floor rock beam are analyzed, such as elastic modulus, coefficient of viscosity, and water pressure. It is shown that the elastic modulus plays the most important role on the deformation of the rock beam. So, for improving the mechanical properties of the rock beam, the reinforcing floor technique has been proposed. On the one hand, it is contributed to improve the ability for resisting floor deformation. On the other hand, it can increase the coefficient of rock viscosity in water damage zones and reduce the speeds of loading and deformation in the whole rock beam. Hydrophobic decompression can effectively reduce the stress on the boundary of the rock beam, and the stability is enhanced. The research results have a guiding significance for determining whether there are water inrush risks in the panel above the confined aquifer.

\section{Introduction}

China is one of the countries that have been affected seriously by damage caused by water in coal mines. The increase in mining depth and widespread application of comprehensive mechanized coal mining and top coal caving have resulted in an increase in floor breaking and water disaster due to mining over pressurized water [1]. Three zones similar to the overlying rock by mining can be found inside the coal floor [2-4]. These are the water-guiding zones broken by mining on the top and the central complete rock, the water-flowing zone on the bottom artesian water, and the water-resisting zone on the central complete rock, which plays an important part in resisting water inrush from the seam floor. During coal seam mining, the thicknesses of the water-guiding and water-flowing zones differ for different mining conditions. Hence, water burst will occur when the thickness of the effective water-resisting zone is not sufficient to bear the water pressure from the bottom artesian water.

Panel floor rock instability is the direct cause of artesian water inrush. Therefore, the jointed rock mass damagecoupling mechanical model [5-7], jointed rock mass 
transfusion-damage-breakage-coupling mathematical model $[8,9]$, elastic-plastic damage microcosmic model [10], and two-body system mechanical model [11] have been established to analyze the conditions and processes of stress deformation and system destabilization. The aim is to identify the critical condition of rock mass dynamic instability. Floor water inrush is the process that results in crack initiation, extension, connection, and eventual failure. The combined action between mining dynamic pressure and hydraulic pressure should be considered in the systematic investigation of the stress and deformation of an effective water-resisting rock beam.

Based on the three zones of the panel floor, this paper takes the water-guiding zone broken by mining as a viscoelastic body and the effective water-resisting rock beam as an elastomer. Under the combined action of mining dynamic and hydraulic pressures, the resistance to bending decreased with the time accumulated for the amount of growth. The deflection and stress of the complete rock beam in the floor change, and a comparison of the maximum bearing capacity of rock mass can determine its stability.

\section{Floor Rock Beam Deformation and Stress Analysis}

\subsection{Floor Load-Bearing Partition and Failure Mechanism.} Coal seam and surrounding rock are in the stress state of equilibrium with the in situ stress state. However, when the coal seam or rock layer is excavated, the stress state of equilibrium is destroyed, causing the surrounding rock stress to be redistributed and the deformation and failure to occur [12]. Figure 1 shows that the coal wall, coal seam, and floor are located in the supercharged region because of the abutment pressure. This region is called the compression zone in which the coal seam floor is compressed. With the advancement of the working face, the floor of this region will transform from the compressed state into the expanded state, resulting in the generation of the floor heave and the appearance of bedding rock cracks. This region is called the inflation-pressure relief zone. As the working face advances once more, the caving rock blocks in the gob become overburdened and compacted. The floor of this region is located in a new pressure zone because of the overburden pressure and the movement from the expansion to the compaction state. Therefore, any section of the coal seam floor always experiences some form of abutment pressure from the compression fracture zone to the postharvest overhang unloading expansion damage zone and from the shear failure zone around the gob and roof caving recompacting zone.

As the working face advances, all points in the floor undergo the process of compression, stress relief, and recompression [13]. A similar simulation experiment result can be observed in Figure 2. The degree of damage of the roof strata is small in an area that ranges from $20 \mathrm{~m}$ to $40 \mathrm{~m}$ behind the working face. The weight of the overburden undertaken by its structure plays an important role in the floor heave. Waterflowing fractures appear in the floor rock strata, and the

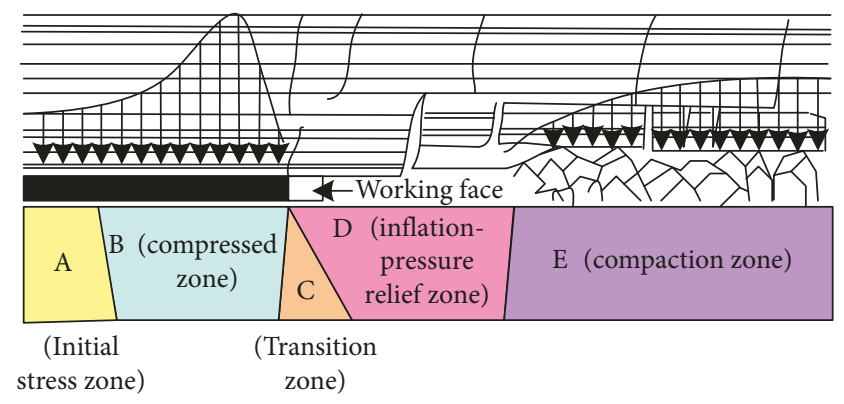

FIGURE 1: Simulated diagram of coal seam floor failure.

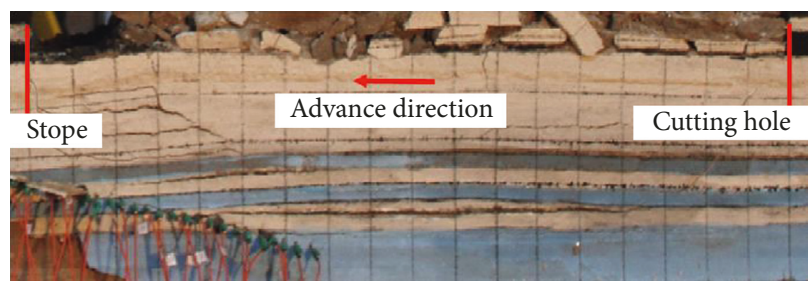

FIgURE 2: Fracture distribution of the floor.

waterproof ability of the strata disappears [14], causing it to transform into a water inrush area. The stress slowly recovers the in situ stress in the floor rock strata of the recompacting zone. The fractures are closed, and the upper boundary stress in the floor increases, which could reduce the possibility of water inrush in the floor. Hence, the inflation-pressure relief zone is the key area for resisting floor water inrush. In this paper, the stress and deformation are analyzed to estimate the water-resisting rock beam stability.

2.2. Mechanical Test. An MTS-815 hydraulic servo-loading test system (Figure 3) is used in the test with a standard sample size of $100 \mathrm{~mm} \times 50 \mathrm{~mm}$. Following the conventional compression tests for postpeak fracture sample and instantaneous fracture strength by single step loading, the maximum load is applied into several levels on the same specimen from step loading, with a load duration of 24 hours. According to the test method for rock, the loading rate is $0.5 \mathrm{MPa} / \mathrm{s}$. The creep value generated at $t$ time after $n+1$ level load is the pre- $\mathrm{N}$ load and the $n+1$-level load increment, which produces the superposition value of creep at the corresponding time. The confining pressure $(4 \mathrm{MPa})$ was also set.

Under a loading of $20 \mathrm{MPa}$, the loading levels are set as $25 \mathrm{MPa}, 30 \mathrm{MPa}, 35 \mathrm{MPa}, 40 \mathrm{MPa}, 45 \mathrm{MPa}$, and $50 \mathrm{MPa}$ as shown Figure 4 . The loading time of all levels is set to 24 hours (1440 min).

According to the experimental data, the creep characteristics of the different loads are analyzed (Figure 5).

The following fitting formula shows the creep of the specimen is in accordance with the deformation characteristics of the Maxwell model as shown in Table 1:

$$
\varepsilon=\frac{1}{\eta} \sigma_{0} t+\frac{\sigma_{0}}{E_{0}}
$$




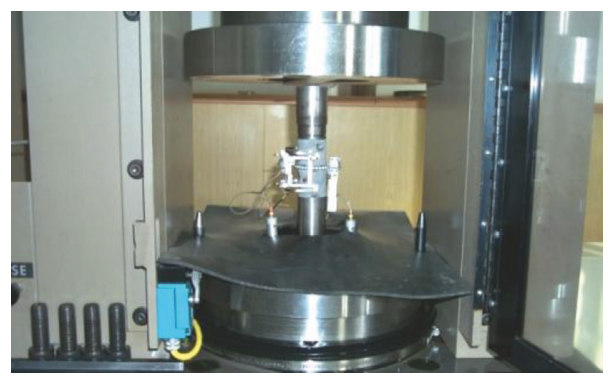

FIGURE 3: Standard rock samples in the test.

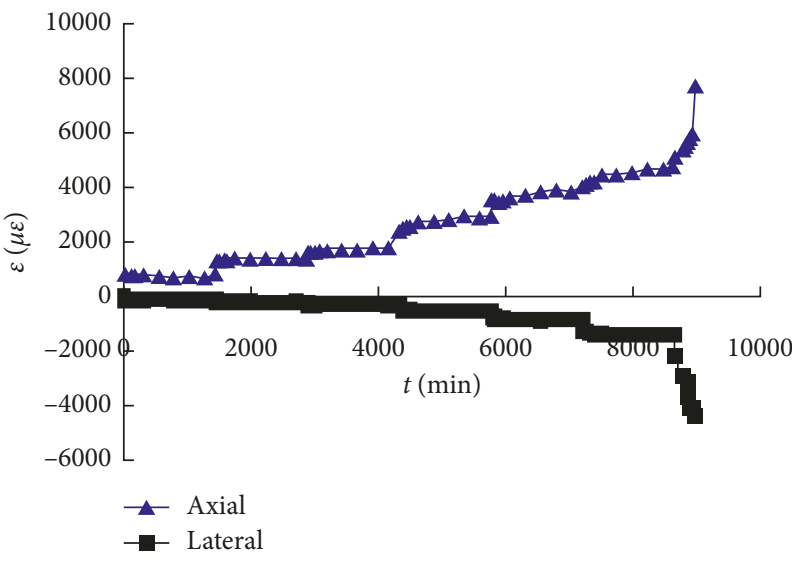

(a)

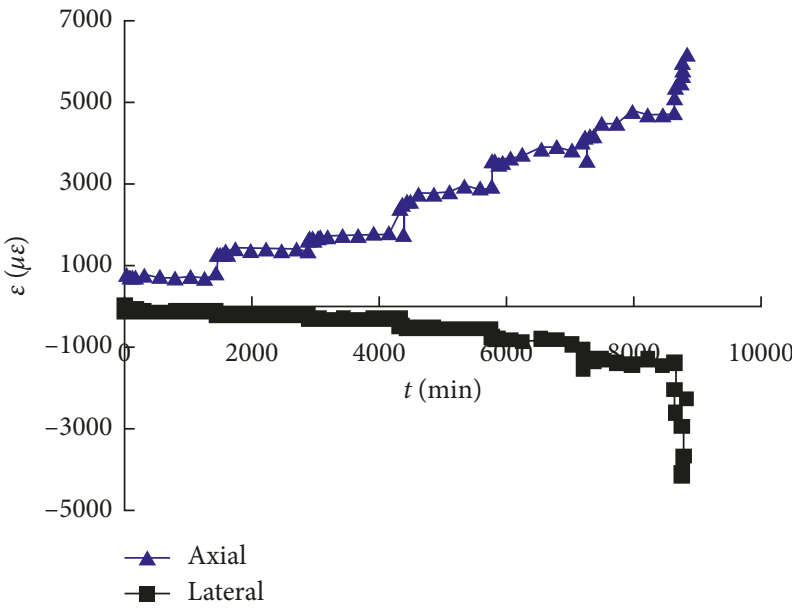

(b)

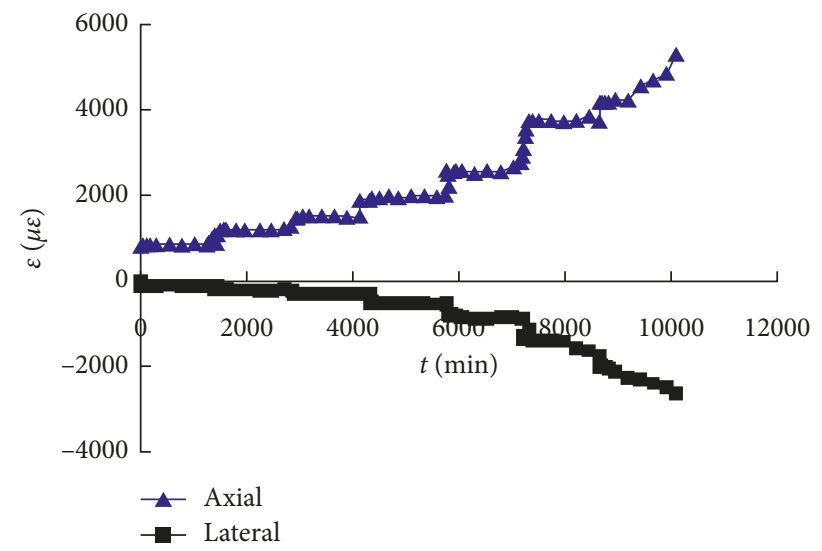

(c)

Figure 4: Axial and lateral creep curves under step loading: (a) Specimen 1; (b) Specimen 2; (c) Specimen 3.

where $E_{0}$ is the initial elastic module, $t$ is the time course, and $\sigma_{0}$ is the initial stress.

The relaxation properties of the rock can be obtained based on the relationship between creep flexibility and the relaxation modulus of elasticity:

$$
\int_{0}^{t} E(t) J(t) d t=t
$$

where $E(t)$ represents the elastic modulus of relaxation and $J(t)$ refers to the creep flexibility.
Figure 6 shows the relaxation characteristics of the specimens under different loads.

2.3. Permeability Test. The permeability test of the standard rock sample is carried out on the rock mechanics experiment system of MTS-815; three samples of sandy mudstone are taken from the floor of coal group A. The seepage fluid is water, and the surrounding rock is set at $4 \mathrm{MPa}$; according to the experimental collection of pore pressure difference, the 


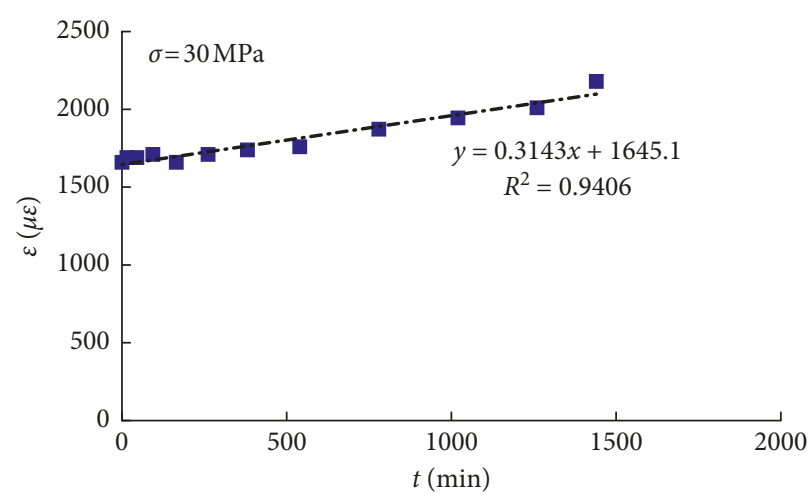

(a)

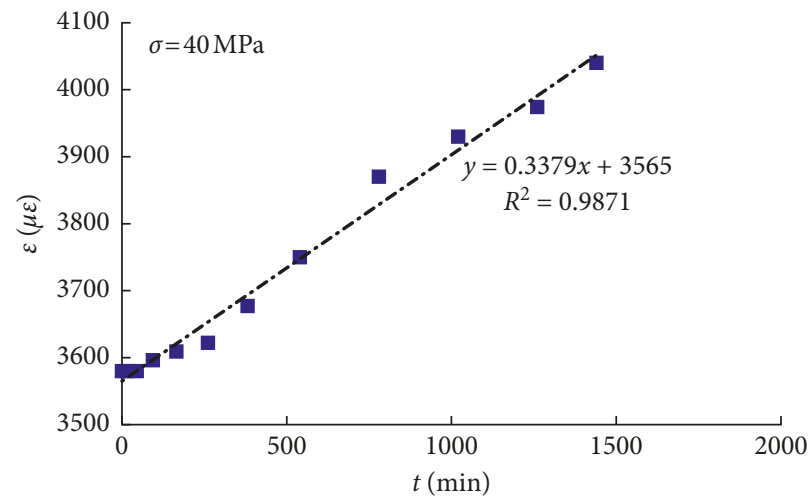

(c)

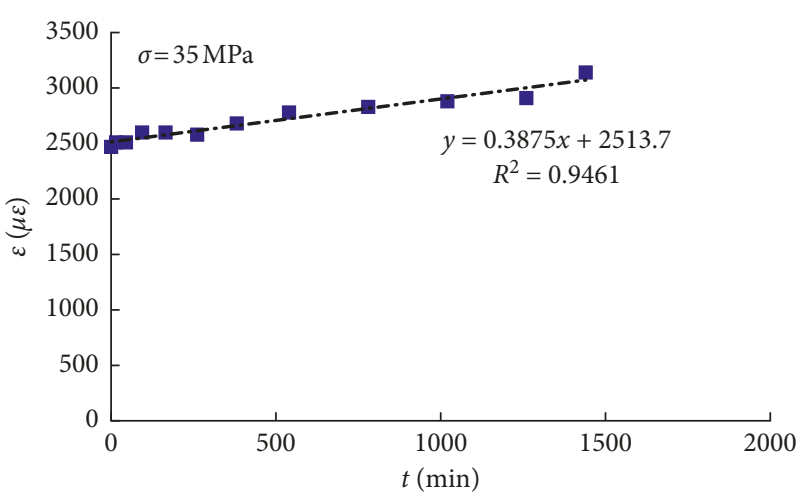

(b)

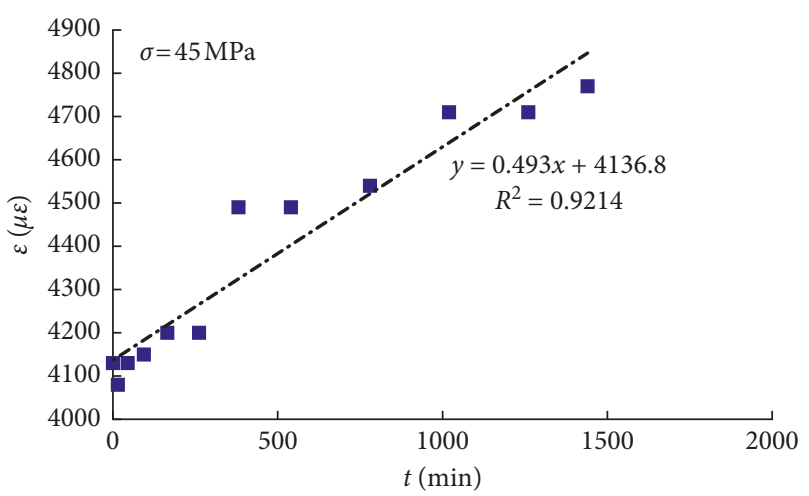

(d)

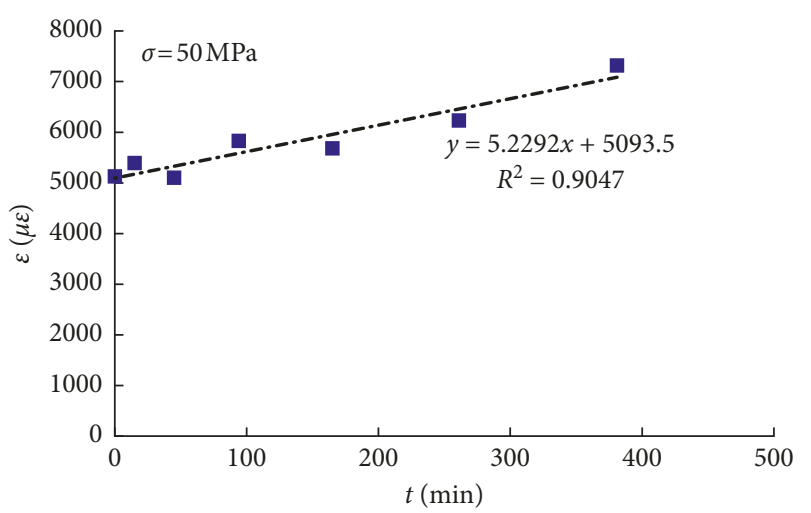

(e)

Figure 5: Axial creep of the specimens: (a) $30 \mathrm{MPa}$; (b) $35 \mathrm{MPa}$; (c) $40 \mathrm{MPa}$; (d) $45 \mathrm{MPa}$; (e) $50 \mathrm{MPa}$.

permeability coefficient $K$ of the Darcy flow is calculated. The method of rock sample encapsulation is shown in Figure 7.

Figure 8 shows the variation rule of the permeability coefficient $K$ with strain $\varepsilon$ of sandy mudstone: (1) at the elastic deformation stage, a small number of microcracks in the sandstone sample began to show tensile deformation, the porosity of the sample increased, and the permeability coefficient $K$ increased gradually; (2) when the strain value is greater than 0.0109 , the permeability coefficient increases sharply and reaches the maximum value $280.01 \times$ $10^{-11} \mathrm{~m} \cdot \mathrm{s}^{-1}$; at this point, the crack in the sample expands and penetrates, forming an obvious macroscopic failure of the structural surface; (3) when the strain is greater than
TABLE 1: Specimen lateral creep parameters at every level of stress.

\begin{tabular}{lccccc}
\hline Axial stress $(\mathrm{MPa})$ & 30 & 35 & 40 & 45 & 50 \\
\hline$E_{0}(\mathrm{GPa})$ & 18.24 & 13.93 & 11.22 & 10.89 & 9.82 \\
$\eta(\mathrm{GPa} \cdot \mathrm{d})$ & 66.28 & 63.01 & 82.21 & 63.4 & 6.64 \\
\hline
\end{tabular}

0.0118 , the permeability coefficient decreases rapidly to about $50 \%$ of the maximum value; (4) when the strain exceeds 0.0134 , the permeability coefficient $K$ decreases slowly and stabilizes around $123.62 \times 10^{-11} \mathrm{~m} \cdot \mathrm{s}^{-1}$. At this stage, the crack structure space of the sample is filled with small broken particles, which reduced the porosity of the sample and decreased the permeability coefficient $K$. 


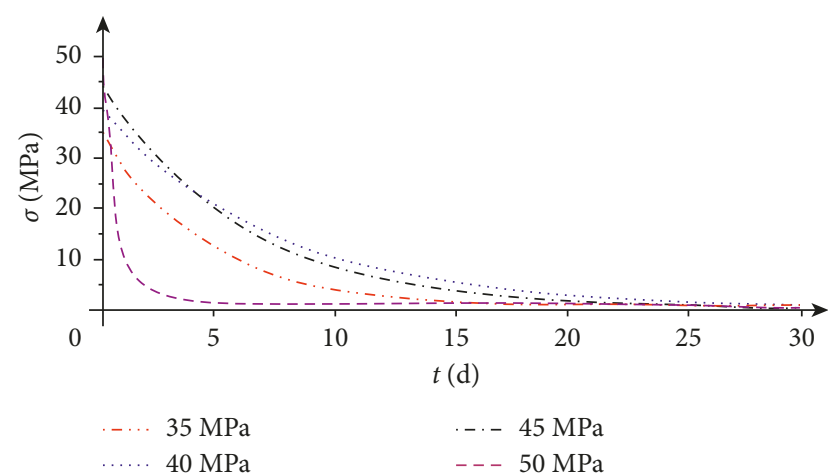

Figure 6: Relaxation characteristics of the specimens under different loads.

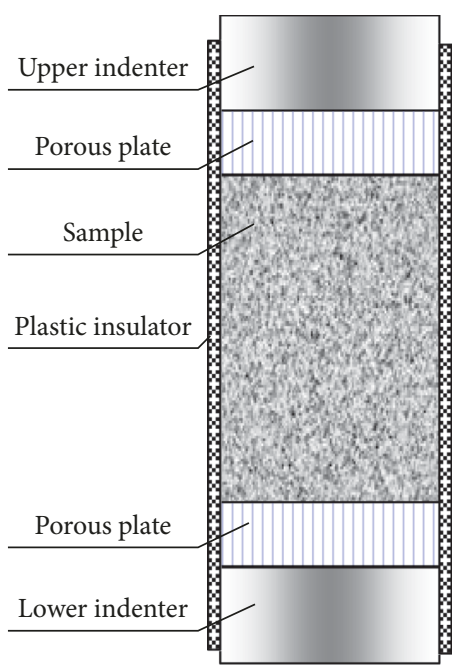

Figure 7: Sample seal.

The test results show that the rock failure will increase the permeability, reduce the risk of water inrush from the floor, reduce the influence of the mining stress on the floor, and make the floor aquifers to not form the channel of water guide, so as to ensure the ability of the water barrier in the floor rock.

2.3. Mechanical Model. It can be seen from Figure 5 that the deformation characteristics of the rock after the peak conform to the Maxwell model. With the increase of the action time, the rock shows significant relaxation characteristics. After coal seam mining, the water-resisting rock strata in the floor could be taken as the clamped beam of both ends to analyze the dip direction of the working face as shown in Figure 9. Within the scope of inflation, pressure relief, and failure zones, the floor is forced by pressure stress $q_{1}(x)$ from the caving gangue of the direct roof. The floor water-resisting rock beam close to the coal seam floor is taken as the mining failure rock beam with a thickness of $h_{1}$, and its mechanical property is considered as viscoelasticity [15-18]. The effective water-resisting rock beam with thickness $h_{2}$ between the confined aquifer and mining failure rock beam represents an elastic deformation sustained by the

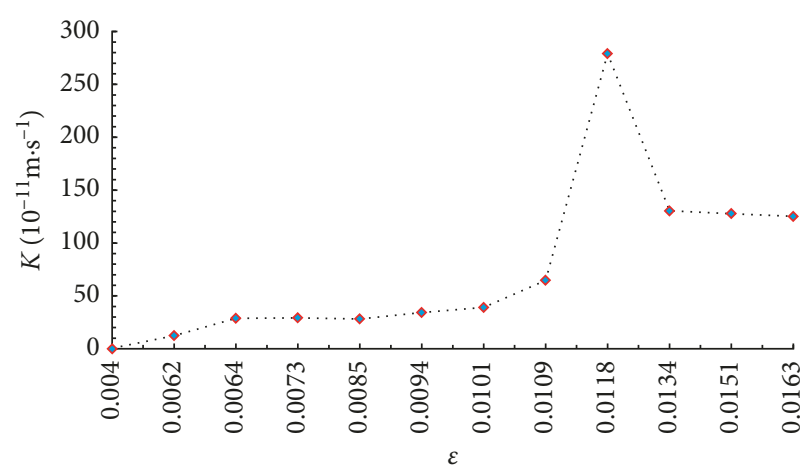

FIGURE 8: The change curve of the permeability coefficient with strain.

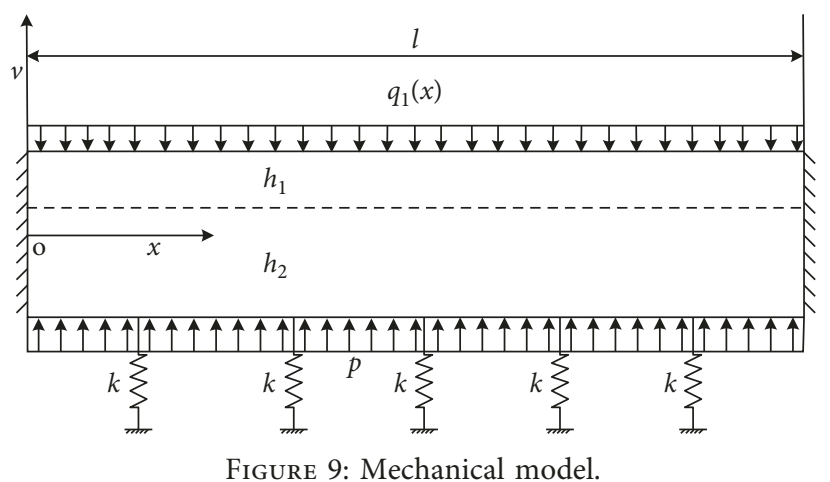

bottom boundary water pressure $p$. Suppose a common displacement boundary between mining failure rock beam and effective water-resisting rock beam exists and it is taken as the medium with certain thickness under the effective water-resisting rock beam as the elastic medium. The medium approximately satisfies the assumption of the Winkler elastic foundation. Hence, the acting force $q_{2}(x)$ in the floor rock beam during the process of pressure relief is represented as follows:

$$
q_{2}(x)=\lambda h-k v,
$$

where $\lambda$ is the comprehensive volume-weight of overburden $\left(\mathrm{N} / \mathrm{m}^{3}\right), h$ is the burial depth of the coal seam $(\mathrm{m}), k$ is the coefficient of the Winkler soil reaction, and $v$ is the flexural deflection of the rock beam.

\subsection{Mechanical Solution of Flexural Deflection in the Floor} Rock Beam. The total energy of the rock beam is composed of three parts of elastic beam (effective water-resisting rock beam) $U_{e}$, viscoelastic beam (mining failure rock beam) $U_{p}$, and external work $\left(U_{q_{1}}+U_{q_{2}}+U_{s}\right)$. That is,

$$
\Pi=U_{e}+U_{p}-U_{q_{1}}-U_{q_{2}}-U_{s} .
$$

Following the virtual work principle and energy functional variational conditions [19], the equation of the rock beam deflection curve $v(x, t)$ should make $\delta \Pi=0$ and $\delta^{2} \Pi>0$. The strain energy and external work in the rock beam are analyzed as follows. 
(1) Strain energy of the effective water-resisting rock beam

$$
U_{e}=\frac{E I}{2} \int_{0}^{l}\left(\frac{\partial^{2} v}{\partial x^{2}}\right)^{2}\left[1-\left(\frac{\partial v}{\partial x}\right)^{2}\right]^{-3} d x
$$

where $E$ is the elasticity $(\mathrm{GPa})$ and $I$ is the cross-sectional moment of inertia.

(2) Strain energy of the mining failure rock beam

$$
\begin{aligned}
U_{p}=\int_{0}^{A} \int_{0}^{\varepsilon} \sigma d \varepsilon d A & =\int_{0}^{l} \int_{0}^{h_{1}} \int_{0}^{\varepsilon} E(t) \\
\cdot \varepsilon d \varepsilon d x d y & =\frac{h_{1}^{3}}{24} \int_{0}^{l} E e^{-(E t / \eta)} \cdot\left(\frac{\partial v}{\partial x}\right)^{2} d x
\end{aligned}
$$

where $Y(t)$ is the loosen modulus, $Y(t)=E e^{-E t / \eta}, \eta$ is the coefficient of viscosity (GPa.h), and $t$ is the time (h).

(3) External work

$$
\begin{aligned}
U_{q_{1}}+U_{q_{2}}+U_{s}= & \int_{0}^{l}-q_{1}(x) \cdot v(x) d x+\int_{0}^{l} q_{2}(x) \\
& \cdot v(x) d x+\int_{0}^{l} p \cdot v(x) d x .
\end{aligned}
$$

The expression of total system potential energy is Equation (7).

Making a first-order variational for potential function $\Pi$, that is,

$$
\begin{aligned}
\delta \Pi= & \frac{E I}{2} \int_{0}^{l} 2 v^{\prime \prime} \delta v^{\prime \prime} d x+\int_{0}^{l} \frac{E \cdot h_{1}^{3} \cdot e^{-(E / \eta) t}}{12} v^{\prime \prime} \delta v^{\prime \prime} d x+\int_{0}^{l} q_{1}(x) \delta v d x-\int_{0}^{l} q_{2}(x) \delta v d x-\int_{0}^{l} p \delta v d x \\
\delta \Pi= & \int_{0}^{l}\left(E I v^{\prime \prime}\right)^{\prime \prime} \delta v d x-\left.\left(E I v^{\prime \prime}\right)^{\prime} \delta v\right|_{0} ^{l}+\left.\left(E I v^{\prime \prime}\right) \delta v^{\prime}\right|_{0} ^{l}+\frac{E \cdot h_{1}^{3} \cdot e^{-(E / \eta) t}}{12} \int_{0}^{l} v^{\prime \prime \prime \prime} \delta v d x-\left.\frac{E \cdot h_{1}^{3} \cdot e^{-(E / \eta) t}}{12} v^{\prime \prime \prime} \delta v\right|_{0} ^{l} \\
& +\left.\frac{E \cdot h_{1}^{3} \cdot e^{-(E / \eta) t}}{12} v^{\prime \prime} \delta v^{\prime}\right|_{0} ^{l}+\int_{0}^{l} q_{1}(x) \delta v d x-\int_{0}^{l} q_{2}(x) \delta v d x-\int_{0}^{l} p \delta v d x .
\end{aligned}
$$

From the starting conditions $\left.v(x)\right|_{x=0, l}=0$, $\partial v(x) /\left.\partial x\right|_{x=0, l}=0$.

The type is simplified to

$$
\delta \Pi=\left(\frac{E h_{2}^{3}}{12}+\frac{E \cdot h_{1}^{3} \cdot e^{-(E / \eta) t}}{12}\right) v^{\prime \prime \prime \prime}+q_{1}(x)-q_{2}(x)-p .
$$

Making a second-order variational for potential function $\Pi$, that is,

$$
\delta^{2} \Pi=E \frac{h_{2}^{3}}{12} \int_{0}^{l}\left(\delta v^{\prime \prime}\right)^{2} d x+\int_{0}^{l} \frac{E \cdot h_{1}^{3} \cdot e^{-(E / \eta) t}}{12}\left(\delta v^{\prime \prime}\right)^{2} d x .
$$

Obviously, formula (10) is greater than 0 .

From $\delta \Pi=0$, formula (9) is changed as follows:

$$
\left(\frac{E h_{2}^{3}}{12}+\frac{E h_{1}^{3} e^{-(E / \eta) t}}{12}\right) v^{\prime \prime \prime \prime}=p+(\lambda h-k v)-q_{1} .
$$

From boundary conditions,

$$
\left.v(x)\right|_{x=0}=0,\left.v(x)\right|_{x=l}=0,\left.\frac{\partial v(x)}{\partial x}\right|_{x=0}=0,\left.\frac{\partial v(x)}{\partial x}\right|_{x=l}=0 .
$$

Finally, the deflection curve $v(x)$ of the floor rock beam is obtained.

\section{Case Analysis}

The coal seams of A1 and A3 (Figure 10) are mined in the A team of Panxie mining area, Huainan Mining Group, with an average dip angle of $16^{\circ}$. The thickness of A1 coal seam ranges from $1.56 \mathrm{~m}$ to $7.77 \mathrm{~m}$ with an average thickness of $2.8 \mathrm{~m}$. The thickness of A3 coal seam ranges from $2.09 \mathrm{~m}$ to $9.17 \mathrm{~m}$ with an average thickness of $5.8 \mathrm{~m}$. The distance ranges from $1 \mathrm{~m}$ to $5 \mathrm{~m}$ between $\mathrm{A} 1$ and $\mathrm{A} 3$, and in some areas, the two coal seams are combined into one coal seam. The floor of the coal seam has strong aquifers of Taiyuan group limestone and Ordovician limestone. A strong aquifer $\mathrm{C}_{3}^{3}$ (lower) which poses a potential risk of water damage for the coal seam mining of $\mathrm{A}$ team under the $\mathrm{A} 3$ with the distance of $29.1 \mathrm{~m}$ can be found. The aquifer thickness of $\mathrm{C}_{3}^{3}$ (lower) is $7.8 \mathrm{~m}$ with an original water pressure of $4.5 \mathrm{MPa}$. The damage degree of the floor is taken into consideration in the process of thick coal seam mining; thus, the coal seam A3 is excavated by slicing, and the thickness of the upper slice is $3.0 \mathrm{~m}$. The inclined length of the panel is $120 \mathrm{~m}$, and the average buried depth of the coal seam is $450 \mathrm{~m}$.

\subsection{Relevant Parameter Confirmation}

(1) Mining failure zone depth

With the increase of mining depth, the weight of overburden, in situ stress, and rock pressure of the working face will also increase, causing the coal seam floor failure to become increasingly serious. A direct proportion 


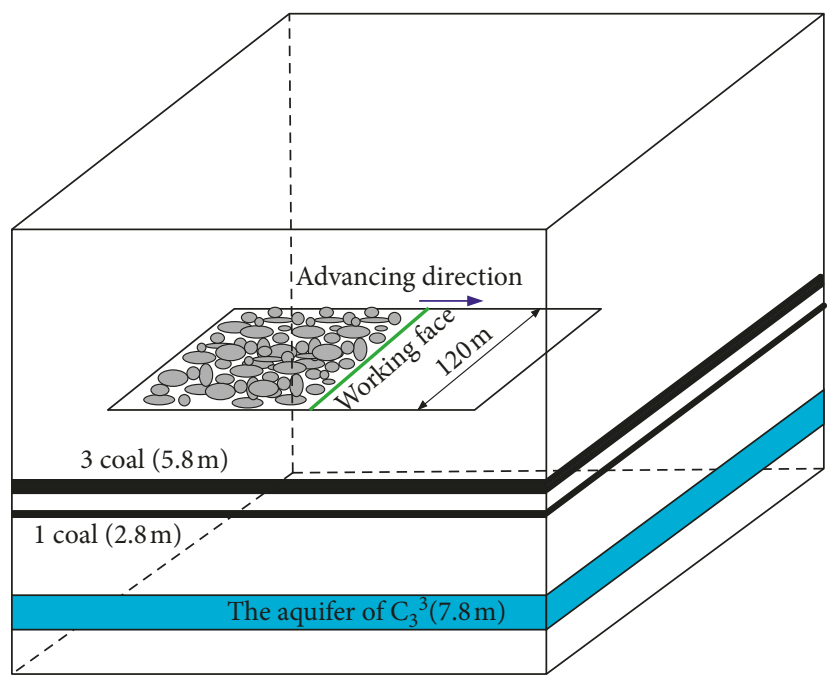

FIgURE 10: Working face arrangement.

relationship between the floor failure depth and the mining depth exists [20]. According to the specific mining conditions of the panel, the mining failure depth $h_{1}$ obtained is $12.47 \mathrm{~m}$ in the floor:

$$
h_{1}=0.0085 h+0.1665 \alpha+0.1079 L-4.3579=12.47 \mathrm{~m},
$$

where $\alpha$ is the dip angle of the coal seam, $0.279 \mathrm{rad}$, and $l$ is the inclined length of the panel, $120 \mathrm{~m}$.

For the distance of $29.1 \mathrm{~m}$ between the floor of A3 and the strong aquifer $\mathrm{C}_{3}^{3}$ (lower), and after the mining of the upper slice, the thickness of the effective water-resisting rock beam $h_{2}$ is as follows:

$$
h_{2}=29.1+2.8-12.47=19.43 \mathrm{~m} \text {. }
$$

(2) Depth of the caving zone and other parameter confirmation

The floor pressure stress $q_{1}(x)$ is formed by the weight of the caving gangue from the direct roof. Considering the strata columnar section of the panel in Figure 3, the lithology is worse in the range $11 \mathrm{~m}$ of A3 coal seam roof, and the roof will cave after the panel is excavated. Then, $q_{1}(x)=2.5 \times$ $10^{4} \times 11=0.275 \mathrm{MPa}$. In formula (11), $\lambda$ is the average unit weight of overburden with the data of $2.5 \times 10^{4} \mathrm{~N} / \mathrm{m}^{3}$, and the Winkler coefficient of soil reaction $k$ is $100 \mathrm{MPa}$.

3.2. Result Analysis. The floor rock beam deformation in different mechanical properties and floor water pressures is studied by analyzing the deflection curve with the time development by changing the elasticity modulus $E$, the coefficient of viscosity $\eta$, and the water pressure $p$.

(1) Influence of elastic modulus on the floor
Before making the drainage measurements in the panel, the floor water pressure $p$ is $4.5 \mathrm{MPa}$. The coefficient of viscosity is $45 \mathrm{GPa} \cdot \mathrm{h}$. When the elasticity moduli $E$ are $15 \mathrm{GPa}, 25 \mathrm{GPa}$, and $35 \mathrm{GPa}$, the deflection curves of floor deformation are shown in Figure 11.

The convex was observed in the deflection curve and the deflection peak was located in the middle right part of the panel. The maximum deflections are $980 \mathrm{~mm}, 592 \mathrm{~mm}$, and $441 \mathrm{~mm}$, respectively, which correspond to the elastic moduli of $15 \mathrm{GPa}, 25 \mathrm{GPa}$, and $35 \mathrm{GPa}$. Hence, improving the elastic mechanical property of floor rock has contributed to the enhancement of the ability to resist deformation.

(2) Influence of coefficient of viscosity on the floor

The floor water pressure is $4.5 \mathrm{MPa}$. And the elastic modulus has the same data of $35 \mathrm{GPa}$. When the coefficients of viscosity $\eta$ are $40 \mathrm{GPa} \cdot \mathrm{h}$ (amount to $1.67 \mathrm{GPa} \cdot \mathrm{d}$ ), $50 \mathrm{GPa} \cdot \mathrm{h}$ (amount to $2.08 \mathrm{GPa} \cdot \mathrm{d}$ ), and $60 \mathrm{GPa} \cdot \mathrm{h}$ (amount to 2.5 GPa.d), respectively, the deflection curves of floor deformation are shown in Figure 12.

Figure 12 shows that under the water-rock coupling action, the maximum deflection of the floor provides the same data with $440 \mathrm{~mm}$ in different coefficients of viscosity. However, the deformation resistance was reinforced when the coefficient of viscosity increased.

(3) Influence of water pressure on the floor

The coefficient of viscosity $\eta$ is $35 \mathrm{GPa} \cdot \mathrm{h}$, and the elastic modulus had the same data as $35 \mathrm{GPa}$. The deflection curves of deformation when the water pressures are at $1.5 \mathrm{MPa}$, 2.5 $\mathrm{MPa}$, and 4.5 $\mathrm{MPa}$ are shown in Figure 13 .

The deflection of the floor rock beam is increased as the water pressure increased. Figure 13 shows that the maximum deflection is $276 \mathrm{~mm}$ with a water pressure of $1.5 \mathrm{MPa}$. The maximum deflection is $441 \mathrm{~mm}$ with a water pressure of 4.5 $\mathrm{MPa}$. The process is an increasing one as time increases. 

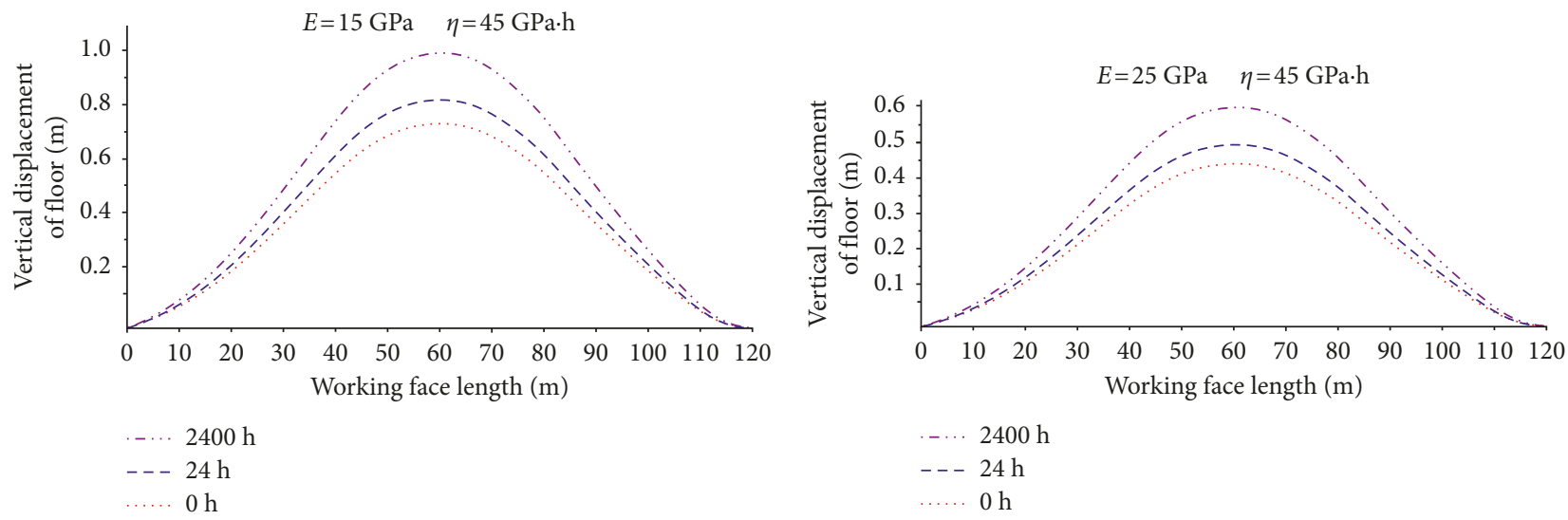

(a)

(b)

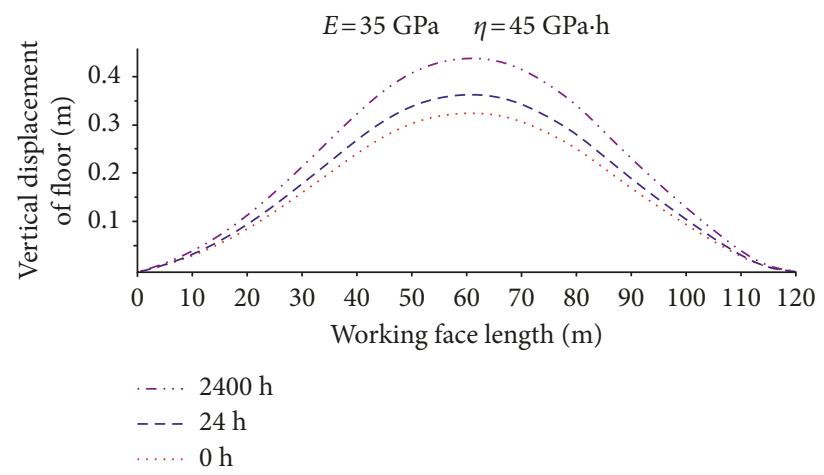

(c)

FIGURE 11: Deformation deflection curve with different elastic moduli. (a) $E=15 \mathrm{GPa}$. (b) $E=25 \mathrm{GPa}$. (c) $E=35 \mathrm{GPa}$.

(4) Stress analysis of the rock beam

Suppose $\left(x_{i}, t_{i}\right)$ is the stationary value point, the discriminant of the extreme value point is

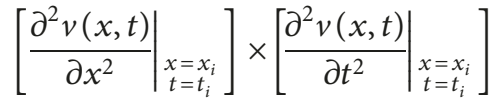

$$
\begin{aligned}
& -\left[\left.\frac{\partial^{2} v(x, t)}{\partial x \partial t}\right|_{\substack{x=x_{i} \\
t=t_{i}}}\right]^{2}>0 .
\end{aligned}
$$

That is,

$$
\begin{gathered}
\left.E I \frac{\partial v^{2}(x, t)}{(\partial x)^{2}}\right|_{\substack{x=x_{i} \\
t=t_{i}}}=M_{\max }, \\
\sigma_{\max }=\frac{M_{\max } h_{\max }}{I_{z}} .
\end{gathered}
$$

Using the tensile stress formula (17) of the floor rock beam, the stress values can be obtained in different depths to judge the stability of the full rock beam. We take $E=35 \mathrm{GPa}, \eta=45 \mathrm{GPa} \cdot \mathrm{h}$, and $p=4.5 \mathrm{MPa}$ as examples to analyze the stress distribution of the full rock beam as shown in Figure 14.

$$
\sigma=E h \frac{\partial v^{2}(x, t)}{(\partial x)^{2}}
$$

The $z$-axis is the stress, the $y$-axis is the distance between the neutral axis of effective water-resisting rock beam and the upper and lower boundary stresses and the $x$-axis is the length of the panel $(\mathrm{m})$.

Figure 14 shows that after the elastic rock beam was forced, it became compressive at the two ends and tense in the middle. The maximum tension stress was found to be greater than the maximum crushing stress, which is in contrast with the neutral axis. The increase in action time caused the appearance of an increased tendency in the maximum tension stress and the maximum crushing stress of the rock beam.

\section{Conclusion}

(1) An analytical model of the viscoelastic rock beam in the floor is established based on the theory of floor "three zones" division in mining above confined water.

(2) By virtual work principle and energy functional variational conditions, the deflection of the effective water-resisting rock beam in the floor and the stress- 

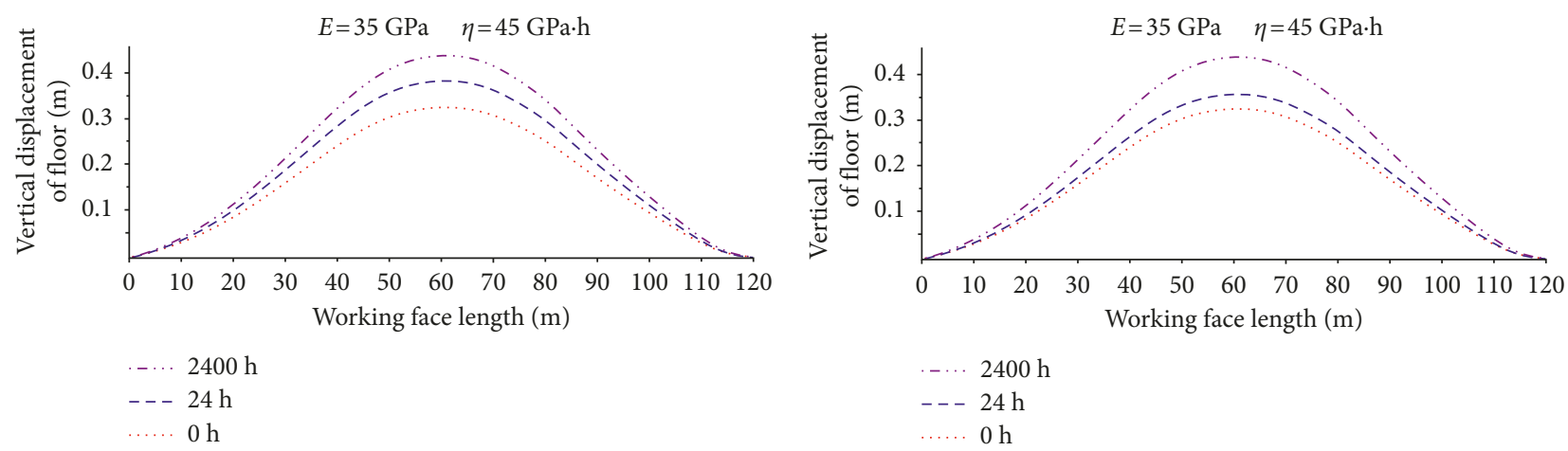

(a)

(b)

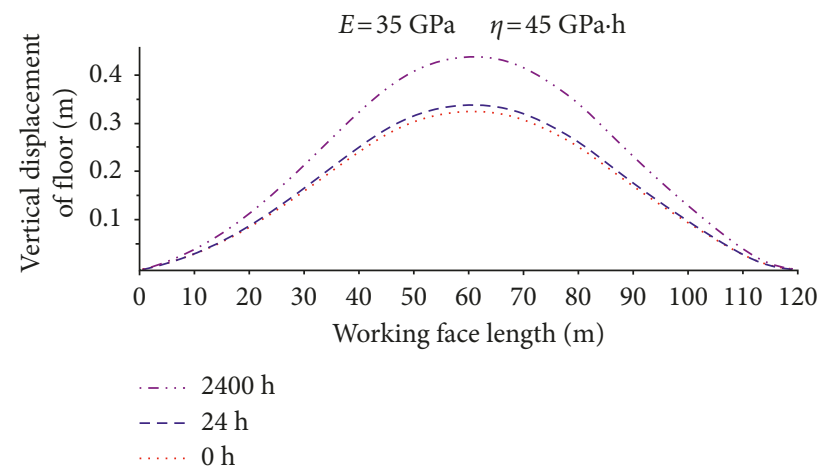

(c)

FIGURE 12: Deformation deflection curve with different viscosity coefficients. (a) $\eta=40 \mathrm{GPa} \cdot \mathrm{h}$. (b) $\eta=50 \mathrm{GPa} \cdot \mathrm{h}$. (c) $\eta=60 \mathrm{GPa} \cdot \mathrm{h}$.

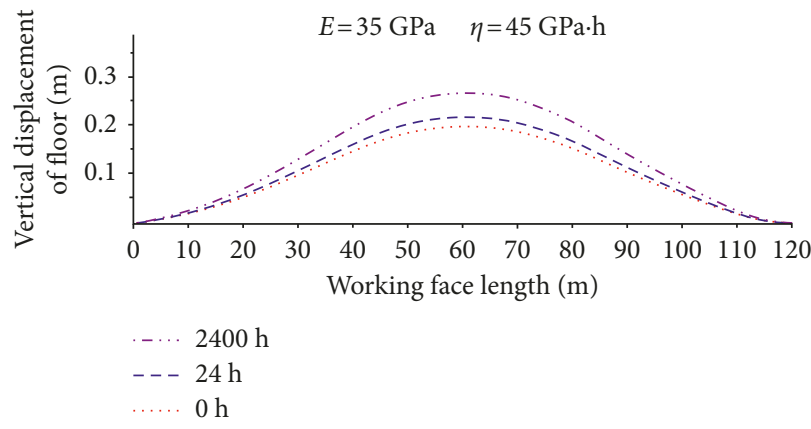

(a)

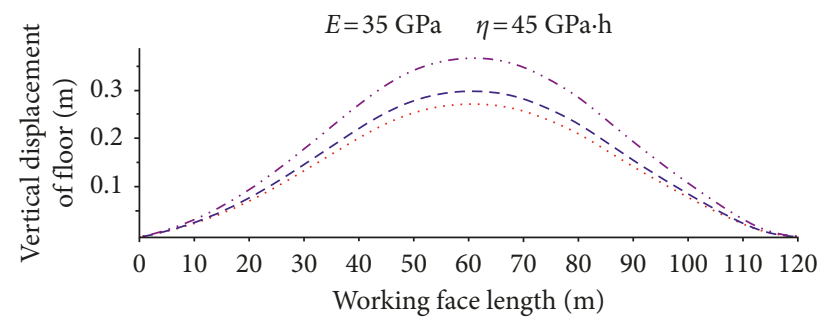

-...2 $2400 \mathrm{~h}$

-. $24 \mathrm{~h}$

..... $0 \mathrm{~h}$

(b)

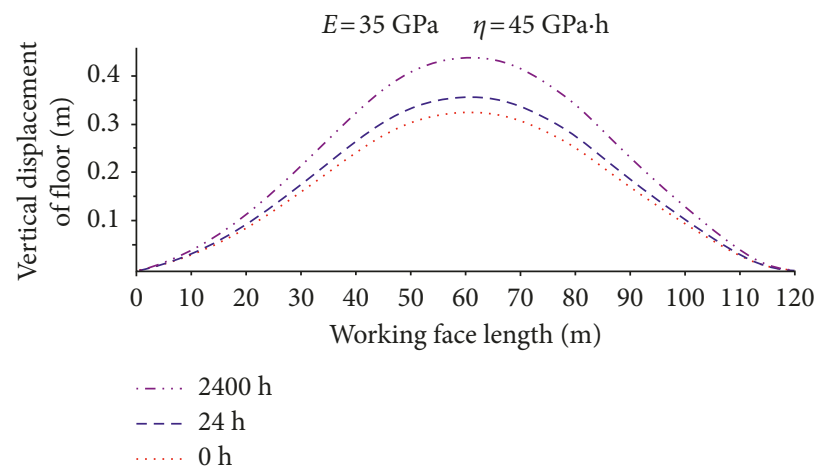

(c)

Figure 13: Deformation deflection curve with different water pressures. (a) $p=1.5 \mathrm{MPa}$. (b) $p=2.5 \mathrm{MPa}$. (c) $p=4.5 \mathrm{MPa}$. 


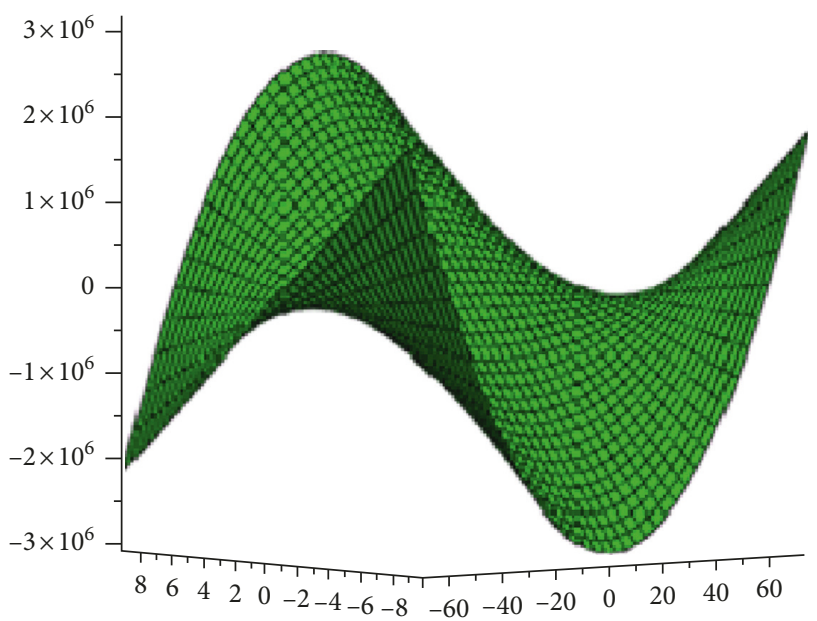

(a)

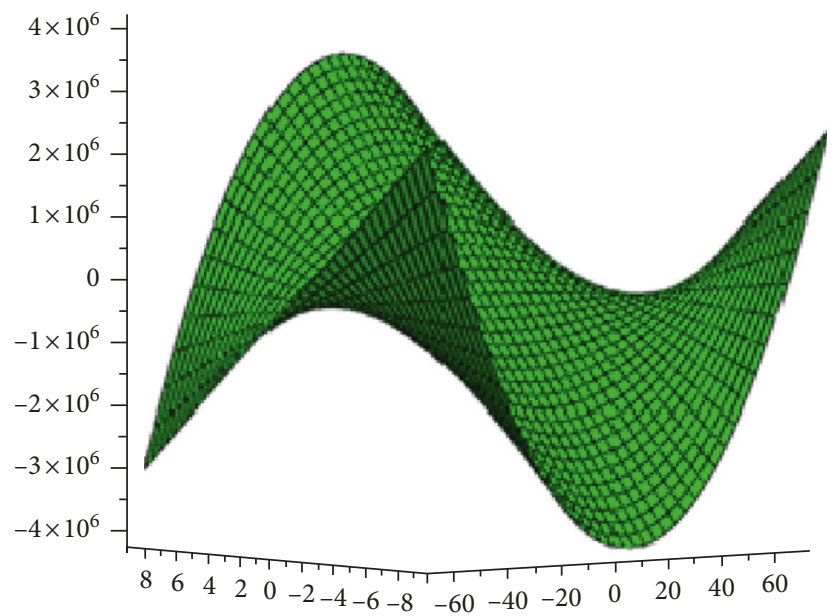

(b)

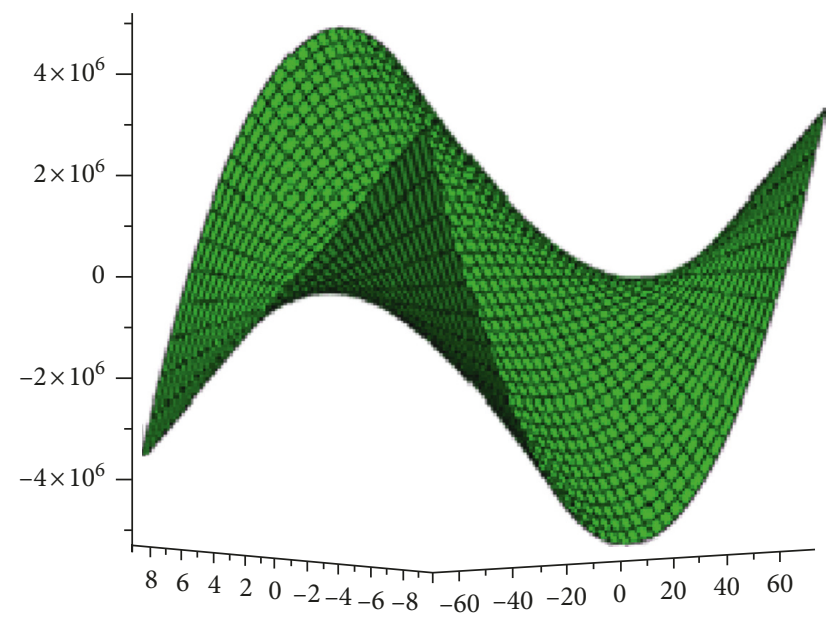

(c)

Figure 14: Rock beam internal stress distribution at different time. (a) $0 \mathrm{~h}$. (b) $24 \mathrm{~h}$. (c) $2400 \mathrm{~h}$.

changing tendency are obtained with the combined action of mining stress and floor water pressure.

(3) Using case analysis, the degrees of influence of the water resistance ability of the rock beam deformation on the elasticity modulus, coefficient of viscosity, and water pressure were obtained. The results indicate that reinforcing the floor caused an improvement in the mechanical property of the rock beam. The reinforcement contributed to the strengthening of the deformation resistance ability of the floor. The coefficient of viscosity was enhanced, and the deformation degree reduced. The drainage measure could reduce the boundary stress efficiently and enhance the ability of the rock beam.

(4) Stress analysis of effective water resistance of the rock beam indicates that stretch yield failure appeared easily in the middle of the panel floor along the dip direction.

\section{Data Availability}

The data used to support the findings of this study are available from the corresponding author upon request.

\section{Conflicts of Interest}

The authors declare that they have no conflicts of interest.

\section{Acknowledgments}

This work was financially supported by the National Natural Science Foundation of China (no. 51674007) and State Key Laboratory for GeoMechanics and Deep Underground Engineering, China University of Mining and Technology (SKLGDUEK1509). The authors gratefully acknowledge the assistance of the Huainan Mining Group, Anhui University of Science and Technology, for providing access to the mine, data, and physical resources necessary to complete this work. 


\section{References}

[1] Z. Wang and H. Liu, Mining Over Confined Aquifer, Coal Industry Press, Beijing, China, 1992.

[2] D. M Pappas and C. Mark, "Behavior of simulated longwall gob material," Report of Investigations/1993, U.S. Department of the Interior Bureau of Mines Ri, Pittsburgh, PA, USA, 1993.

[3] M. D. G. Salamon, "Displacements and stresses induced by longwall mining in coal," in Proceedings of 7th ISRM Congress, International Society for Rock Mechanics, Aachen, Germany, September 1991.

[4] B. Li, "Down"Three Zones"in the prediction of the water inrush from coal bed floor aquifer-theory development and application," Journal of Shandong Institute of Mining and Technology, vol. 18, no. 4, pp. 11-15, 1999.

[5] S. Dong, "Some key scientific problem s on water hazards frequently happened in China's coal mines," Journal of China Coal Society, vol. 35, no. 1, pp. 66-71, 2010.

[6] S. Li, "The crack and damage mechanism study of jointed rock with complex stress," Chinese Journal of Rock Mechanics and Engineering, vol. 18, no. 2, pp. 142-146, 1999.

[7] H. Yavuz, "An estimation method for cover pressure reestablishment distance and pressure distribution in the goaf of longwall coal mines," International Journal of Rock Mechanics \& Mining Sciences, vol. 41, no. 2, pp. 193-205, 2004.

[8] S. Zheng and Z. Wei-Shen, "Theory analyzing of the jointed rock fluid and damage coupling model," Chinese Journal of Rock Mechanics and Engineering, vol. 20, no. 2, pp. 156-159, 2001.

[9] Y. Zhao, P. Cao, and Y. Wang, "Coupling model of seepagedamage-fracture in fractured rock masses and its application," Chinese Journal of Rock Mechanics and Engineering, vol. 27, no. 8, pp. 1634-1643, 2008.

[10] J. Zhao, Z. Zhang, and Z. Liu, "3D numerical simulation of elasto-plastic damage and failure process of marble rock," Chinese Journal of Geotechnical Engineering, vol. 30, no. 9, pp. 1309-1315, 2008.

[11] H. Xie, Z. Chen, and H. Zhou, "Study on two-body mechanical model based on interaction between structural body and geo-body," Chinese Journal of Rock Mechanics and Engineering, vol. 24, no. 9, pp. 1457-1464, 2005.

[12] M. Qian and P. Shi, Mine Ground Pressure and Stratum Control, China University of Mining and Technology Press, Xuzhou, China, 2003.

[13] S. Liu, Mechanism of Water Inrush from Coal Seam Floor and Continuous Survey of Fractured Zones in Coal Seam Floor, China University of Mining Technology, Doctoral Dissertation, Xuzhou, China, 2008.

[14] L Fan and S Liu, "A conceptual model to characterize and model compaction behavior and permeability evolution of broken rock mass in coal mine gobs," International Journal of Coal Geology, vol. 172, pp. 60-70, 2017.

[15] H. Lu, D. Yao, X. Liang et al., "Analytical solution of stress in a transversely isotropic floor rock mass under mining," Chinese Journal of Underground Space and Engineering, vol. 9, no. 5, pp. 1050-1056, 2013.

[16] B. Fu, Research on Floor Partition Characteristics and Stability under Water-Rock Coupling Action, Anhui University of Science and Technology, Huainan, China, 2013.

[17] Y. M. Song, S. P. Ma, X. B. Yang et al., "Experimental study on the dynamic displacement evolution of fault in stick-slip process," Chinese Journal of Geophysics, vol. 55, no. 1, pp. 171-179, 2012.

[18] J. P. Seidle, M. W. Jeansonne, D. J. Erickson et al., "Application of matchstick geometry to stress dependent permeability in coals," in Proceedings of Spe Rocky Mountain Regional Meeting, Casper, WY, USA, May 1992.

[19] Y. Long, New Theory of Energy Principle, China Building Industry Press, Beijing, China, 2007.

[20] Coal Industrial Development Bureau of China, Coal Pillar Setting of Buildings, Water Bodies, Railways and Main Shaft and Mining regulations, Coal Industry Press, Beijing, China, 2000. 


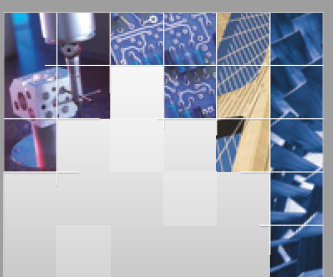

\section{Enfincering}
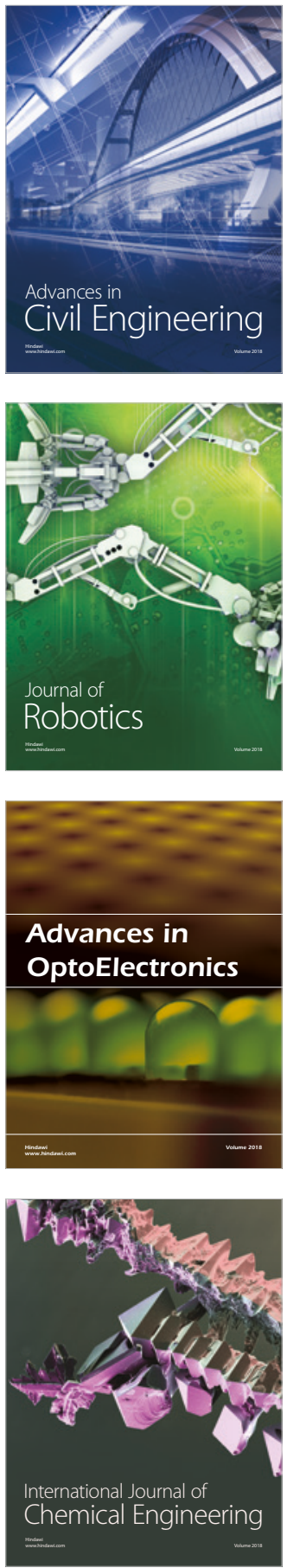

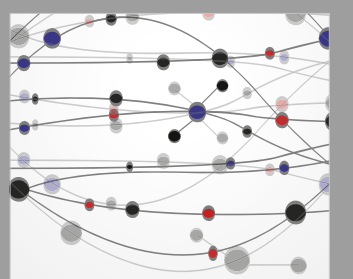

\section{Rotating \\ Machinery}

The Scientific World Journal

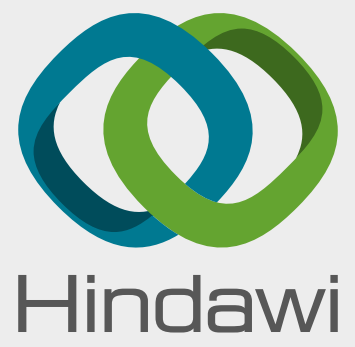

Submit your manuscripts at

www.hindawi.com
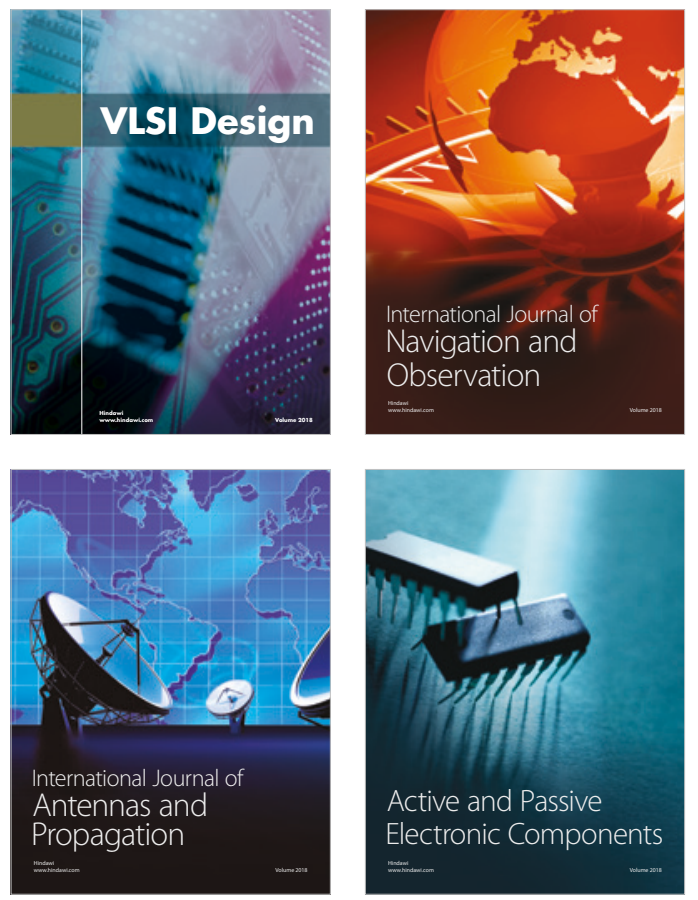
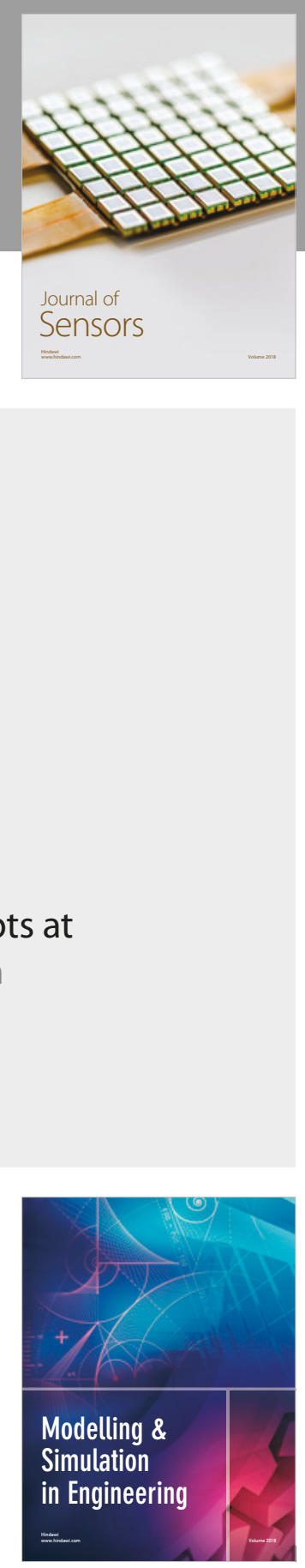

\section{Advances \\ Multimedia}
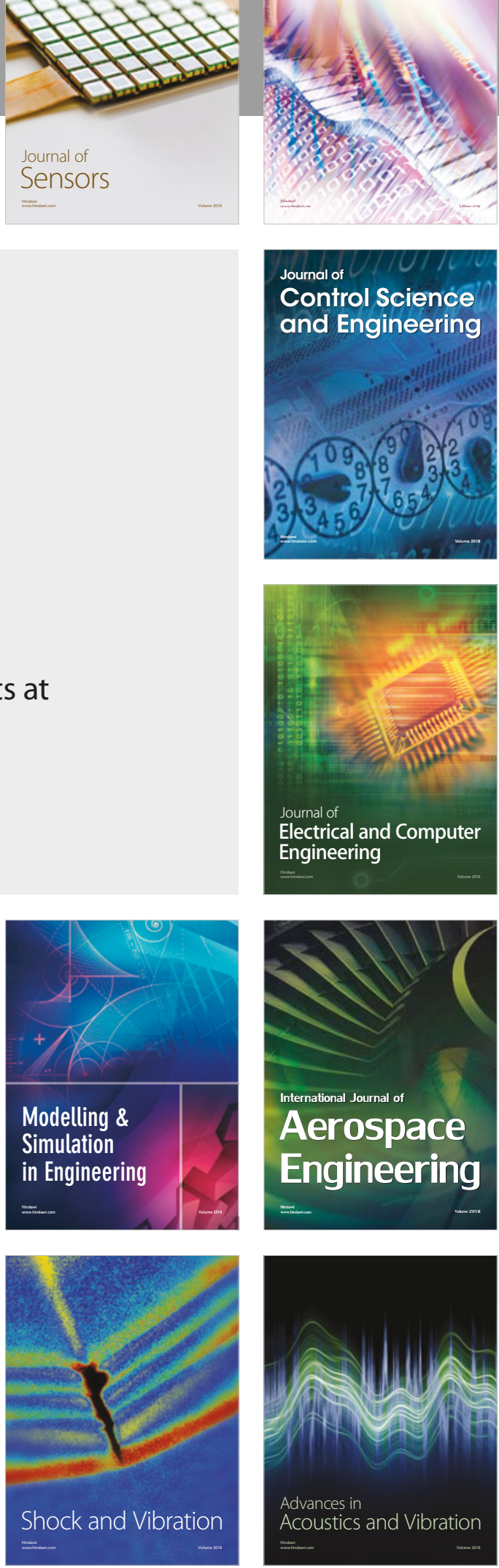